\title{
Editorial
}

\section{A New Way to Read, Write, and Review for $\operatorname{CORR}^{\mathrm{R}}$}

\author{
Lee Beadling BA, Seth S. Leopold MD
}

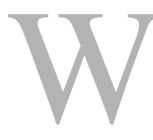

ebsites for media sources are ubiquitous. One cannot imagine a newspaper, scientific journal, or TV network existing in 2016 without a web presence. In fact, many publications that once were print-based, including Clinical Orthopaedics and Related Research $^{\circledR}$, now depend on web-based services to a far-greater degree than they do on paper distribution. You, our readers, have demonstrated how you prefer to consume the timely, highquality orthopaedic studies $\operatorname{CORR}^{\circledR}$

\footnotetext{
The authors certify that they, or any members of their immediate families, have no commercial associations (eg, consultancies, stock ownership, equity interest, patent/ licensing arrangements, etc) that might pose a conflict of interest in connection with the submitted article.

All ICMJE Conflict of Interest Forms for authors and Clinical Orthopaedics and Related Research ${ }^{\mathbb{R}}$ editors and board members are on file with the publication and can be viewed on request.

The opinions expressed are those of the writers, and do not reflect the opinion or policy of $C O R R^{\circledR}$ or The Association of Bone and Joint Surgeons ${ }^{\circledR}$.
}

L. Beadling BA, S. S. Leopold MD ( $₫)$

Clinical Orthopaedics and Related

Research, Philadelphia, PA 19103, USA

e-mail: sleopold@clinorthop.org publishes: In 2015, users downloaded individual manuscripts in full-text form nearly 2 million times, either from our publisher's website or from the freely available manuscripts archived on PubMed Central. By contrast, although our print-subscription base is robust, it is measured in the thousands, not the millions.

That being so, we have spent the last year making our website the perfect place for our readers to find the best available evidence they need to inform the clinical decisions they make, as well as to keep up on the latest clinically relevant laboratoryscience research. The site also provides tools for our authors to make scientific reporting easier and more intuitive, and we are finalizing a webbased toolkit for our peer reviewers, as well. Here are some of the features we think you will enjoy.

For $\boldsymbol{C O R R}^{\circledR}$ Readers: The new CORR ${ }^{\circledR}$ website highlights the diversity of content we now publish, and makes our material more accessible. Now you can easily scroll through all of our dozen-plus regular columns on big-picture topics, our thoughtful CORR Insights ${ }^{\circledR}$ commentaries that render complex topics more readable, our Editor's Spotlight manuscripts with accompanying Take-5 Interviews, the monthly editorial, and links to our Facebook and Twitter feeds. Of course, the site also makes it easier for readers to access the first-quality peerreviewed scientific content for which $\operatorname{CORR}^{\circledR}$ is justifiably known, through searches by title, author, subspecialty, and journal issue. Readers of our journal can browse through the current issue, or past issues, and daily updates of our Online First ${ }^{\mathrm{TM}}$ manuscripts prior to their appearance in an issue. If you are one of the thousands of new $C_{C O R R^{\circledR}}$ users who are coming to us through the numerous US and international societies now offering their members full-text access to our Journal as a benefit of society membership, we welcome you, and we know you will enjoy the time you spend on our site.

For $\boldsymbol{C O R R}^{\circledR}$ Authors: Readers consistently tell us how much they enjoy our journal's clear approach to scientific reporting; we ask our authors to organize their papers around questions and answers, because this enables busy readers to get what they need quickly. But authors tell us that adhering to this approach is not always easy. Our unique web-based articlebuilding tool for clinical research manuscripts decreases the work of manuscript submission by walking authors through the creation of a 
question-driven scientific manuscript, and at the end produces a downloadable version of their article, formatted and ready for submission. In the months to come, we will upload tools for other article types, including systematic reviews, meta-analyses, and laboratory (nonclinical) research articles. Additionally, we offer guidelines to our many editorials about scientific writing in general and specifically about writing for $C O R R^{\circledR}$.

For $\operatorname{CORR}^{\circledR}$ Reviewers: The quality of the material we publish depends critically upon thorough and thoughtful peer review. Reviewers, though, volunteer their time, and our best reviewers are much in demand both at $C O R R^{\circledR}$ and elsewhere. Naturally, we want to make the most of the energy our referees exert on behalf of our readers; in short, to get more usable suggestions from them while consuming less of their time. With that in mind, we now are putting the finishing touches on our online reviewer tool, which will point reviewers towards the key questions to ask of each manuscript, help them from overlooking key methodological elements, and allow our referees to do better work in less time than ever. We will announce when the reviewer tool goes live (and share more about its special features), and we will include links to publications that will aid you in reviewing for $C O R R^{\circledR}$ and other journals.

In a simpler time, $\operatorname{CORR}^{\circledR}$ had readers who flipped through paper pages. We now have "users," who download content from our website and use our online tools. The move from holding a journal in one's hands to downloading content to a mobile device with the swipe of a finger has occurred with surprising speed. And this has, by and large, been a good thing. Tools for reviewers and authors, and a rich, multimedia experience for readers-all continuously updated with the newest content easily identified-reward the user so much more than might any passive exercise involving printed pages.

We value our users, new and old, and are delighted to invite them to enjoy all that Clinical Orthopaedics and Related Research ${ }^{\circledR}$ has to offer at www.clinorthop.org. And, as always, we are glad to take any suggestions and comments from our users-send your thoughts to us at eic@clinorthop.org.

Acknowledgement The authors acknowledge Mr. Brian Robinson, whose suggestions to improve the new $C O R R^{\circledR}$ website were absolutely invaluable, and whose ideas about how to share them in this essay also were very helpful. 